\title{
Rhodium Pair-Sites on Magnesium Oxide: Synthesis, Characteriza- tion, and Catalysis of Ethylene Hydrogenation
}

\author{
Dong Yang, ${ }^{a}$ Pinghong Xu, ${ }^{a}$ Erjia Guan, ${ }^{a}$ Nigel D. Browning, ${ }^{b}$ Bruce C. Gates ${ }^{a^{*}}$ \\ ${ }^{a}$ Department of Chemical Engineering \& Materials Science, University of California, Davis, California 95616, United \\ States \\ ${ }^{b}$ Fundamental and Computational Sciences, Pacific Northwest National Laboratory, 902 Battelle Blvd, Richland, \\ Washington 99352, United States
}

Corresponding Author: *E-mail; bcgates@ucdavis.edu (B.C.G.)

\begin{abstract}
:
Supported rhodium acetate dimers were prepared by the reaction of $\mathrm{Rh}_{2}(\mathrm{OAc})_{4}(\mathrm{OAc}$ is acetate) with highly dehydroxylated $\mathrm{MgO}$ powder and characterized by extended X-ray absorption fine structure and infrared (IR) spectra, which show that the supported species were well represented as $\mathrm{Rh}_{2}(\mathrm{OAc})_{3}$, with each $\mathrm{Rh}$ atom on average bonded to one oxygen atom of the $\mathrm{MgO}$ surface. Aberration-corrected scanning transmission electron microscopy gave images of Rh atoms in pairs on the MgO. The supported rhodium dimers were probed with a pulse of $\mathrm{CO}$, and the IR spectra indicate a $\mathrm{Rh}$ (II) species with weakly bonded carbonyl ligands; the sharpness of the $v_{\mathrm{CO}}$ band indicates highly uniform surface species. Further treatment in $\mathrm{CO}$ led to breakup of the rhodium dimers into mononuclear species; such fragmentation took place in other treatment gases as well, with the degree of fragmentation decreasing in the order $\mathrm{CO}>\mathrm{C}_{2} \mathrm{H}_{4}>$ helium. The fragmentation is inferred on the basis of IR spectra to have proceeded through intermediate $\mathrm{Rh}_{2}$ species without acetate ligands. In contrast, rhodium dimers were reduced and not fragmented in the presence of $\mathrm{H}_{2}$ at $353 \mathrm{~K}$, but at higher temperatures the rhodium aggregated to give larger clusters. The supported species catalyzed ethylene hydrogenation at 298 $\mathrm{K}$ and 1 bar at a $\mathrm{H}_{2}$ :ethylene molar ratio of 4 ; after $27 \mathrm{~h}$ of catalysis in a once-through flow reactor, acetate ligands were removed from the dimers, and some of them fragmented, as shown by IR spectroscopy. The intermediate dirhodium species without acetate ligands are two or three orders of magnitude more active as catalysts than the supported mononuclear rhodium species or those present predominantly as $\mathrm{Rh}_{2}(\mathrm{OAc})_{3}$, respectively.
\end{abstract}

KEYWORDS: supported rhodium dimer; supported single-site catalyst; supported pair-site catalyst; metal fragmentation; metal aggregation; ethylene hydrogenation.

\section{Introduction}

Single-site catalysts consisting of isolated metal atoms on solid surfaces have emerged as a class of materials with surprising new properties; the discovery of these supported metal complex catalysts has been facilitated by atomic-resolution images of the isolated metal atoms, obtained by aberration-corrected scanning transmission electron microscopy (STEM) [1-5]. Single-metal-atom complex catalysts are most commonly used in solution, and the discovery of better ones typically results from investigations of new metal-ligand combinations; however, the metal nuclearity is also important, because metal centers neighboring each other may have reactivities different from those of isolated metal centers $[1,6]$. Metal complexes with pairs of metal atoms require stabilization by ligands-and solid surfaces in prospect can serve as such ligands. $\mathrm{MgO}$ has been found to stabilize dimeric rhodium species (having Rh-Rh bonds) that catalyze hydrogenation of olefins-with major differences between isolated and paired rhodium centers as catalysts for hydrogenation of the bifunctional molecule 1,3-butadiene indicating a unique role of the neighboring rhodium centers $[7,8]$. Rhodium catalysts with controlled nuclearities are especially appealing in prospect because of the versatility of rhodium as a catalyst, in forms ranging from mononuclear complexes [9-12] to clusters [13-16] to metallic particles [17-19]. 
We now report an extension of this class of catalyst, consisting of pairs of Rh centers on a support. The catalyst was synthesized from $\mathrm{MgO}$-supported dinuclear rhodium species formed by adsorption of the rhodium acetate dimers $\mathrm{Rh}_{2}(\mathrm{OAc})_{4}$ (OAc is acetate). The supported species were characterized by infrared (IR) and X-ray absorption spectra complemented by STEM images that provide the first direct evidence of supported rhodium pair sites. High-area MgO powder was chosen as the support because it consists of light atoms-for a strong contrast with $\mathrm{Rh}$ atoms in STEM - and because it is highly crystalline, facilitating the imaging of the support surfaces. Processes involving the fragmentation of supported dinuclear rhodium species to give mononuclear $\mathrm{Rh}$ sites were monitored spectroscopically with the samples in various gas atmospheres, some leading to the aggregation of the rhodium into small clusters. The catalytic properties of the paired Rh centers were compared with those of single-site rhodium species and rhodium dimers without acetate ligands, on the same support. Ethylene hydrogenation was chosen as a test reaction because it takes place under such mild conditions that aggregation of the rhodium during catalysis is limited and because ethylene forms ligands on the rhodium that are identifiable by IR spectroscopy. The results demonstrate that the dirhodium species without acetate ligands are much more active catalytically than either the supported dirhodium species with acetate ligands or supported mononuclear rhodium species.

\section{Experimental methods}

\subsection{Sample synthesis}

Sample synthesis and handling were performed with the exclusion of moisture and air by use of standard Schlenk line techniques and inert-atmosphere glove boxes.

The precursor $\mathrm{Rh}_{2}(\mathrm{OAc})_{4}$ (99\%) was purchased from Strem. The MgO support (Matheson Coleman \& Bell) was calcined in flowing $\mathrm{O}_{2}$ at $973 \mathrm{~K}$ for $4 \mathrm{~h}$ and then evacuated for $16 \mathrm{~h}$ at $973 \mathrm{~K}$, giving a material with a BET surface area of $70 \mathrm{~m}^{2} / \mathrm{g}$. $\mathrm{H}_{2}$ was supplied by Airgas (99.995\%) or generated by electrolysis of water in a Balston generator (99.99\%) and purified by passage through traps containing reduced $\mathrm{Cu} / \mathrm{Al}_{2} \mathrm{O}_{3}$ and activated zeolite $4 \mathrm{~A}$ to remove traces of $\mathrm{O}_{2}$ and moisture, respectively. Helium (Airgas, 99.999\%), ethylene (Airgas, 99.99\%), and CO (10\% in helium) were purified by passage through similar traps.

To prepare the supported catalyst containing $1.0 \mathrm{wt} \% \mathrm{Rh}$, the precursor $\mathrm{Rh}_{2}(\mathrm{OAc})_{4}(21.5 \mathrm{mg})$ and calcined $\mathrm{MgO}$ (1.0 g) were slurried in dried and deoxygenated n-pentane (Fisher, 99\%) at room temperature. The slurry was kept at this temperature with mixing for a day, and thereafter the solvent was removed by evacuation for a day, leaving all the rhodium on the support; thus, the rhodium loadings were determined from the masses of rhodium and support present initially. The slurry was initially green in color (the color of the $\mathrm{Rh}_{2}(\mathrm{OAc})_{4}$ precursor), but the powder changed to light blue in color after one day of reaction, and the solution become clear and colorless, consistent with the complete uptake of the rhodium precursor with the support even before the solvent was removed by evacuation. The resultant supported catalyst was stored in an argon-filled glove box $\left(<1 \mathrm{ppm}_{2}\right.$ and $\left.<1 \mathrm{ppm} \mathrm{H}_{2} \mathrm{O}\right)$.

\subsection{Infrared spectroscopy}

A Bruker IFS 66v/S spectrometer with a spectral resolution of $2 \mathrm{~cm}^{-1}$ was used to collect transmission IR spectra of the supported samples. In an argon-filled glovebox, each supported sample (typically, $40 \mathrm{mg}$ ) was pressed into a thin wafer; when the sample was the $\mathrm{Rh}_{2}(\mathrm{OAc})_{4}$ precursor, $5 \mathrm{mg}$ of that solid was mixed with $50 \mathrm{mg}$ of $\mathrm{KBr}$, and the mixture was pressed into a wafer). Each of these samples was mounted in a cell (In-situ Research Institute, South Bend, IN) for transmission spectroscopy. The cell was connected to a vacuum system with a base pressure of $10^{-4}$ bar, which allowed recording of spectra with gases (helium, $\mathrm{H}_{2}$, ethylene, or $\mathrm{CO}$ ) flowing through the cell at temperatures in the range of 298-393 $\mathrm{K}$ and atmospheric pressure. Each spectrum is the average of a number of scans ranging from 8 to 128 .

\subsection{X-ray absorption spectroscopy}

$\mathrm{X}$-ray absorption spectra were recorded at X-ray beamline 4-1 at the Stanford Synchrotron Radiation Lightsource (SSRL). The storage ring electron energy and ring current were $3.0 \mathrm{GeV}$ and $300 \mathrm{~mA}$, respectively. A double-crystal $\mathrm{Si}(220)$ monochromator was detuned by $15-20 \%$ at the $\mathrm{Rh}$ $\mathrm{K}$ edge to minimize the effects of higher harmonics in the $\mathrm{X}$-ray beam. The experimental methods are essentially the same as those described elsewhere [8].

\subsection{STEM imaging}

Samples for imaging by STEM were prepared by dipping a 200-mesh lacey-carbon-coated cooper grid (Ted-Pella) into the initially prepared catalyst powder in the glovebox. Samples were transported to the microscope and mounted onto a sample holder in an argon-filled glovebag and then transferred under an argon blanket to the microscope with a maximum period of air exposure of $3 \mathrm{~s}$. Samples were imaged with an aberration-corrected FEI Titan $80 / 300 \mathrm{~S}$ operating at $300 \mathrm{keV}$. The convergence angle was $35.6 \mathrm{mrad}$; the HAADF collection inner angle was $\sim 75 \mathrm{mrad}$. To minimize artifacts in the images caused by beam damage, the microscope was first aligned for one region of the sample, and then the beam was shifted to a nearby region for image acquisition.

\subsection{Catalytic activity testing}

Ethylene hydrogenation catalysis was carried out in a conventional laboratory once-through tubular plug-flow reactor at $298 \mathrm{~K}$ and 1 bar. The catalyst (10 to $50 \mathrm{mg}$ per 
sample) was diluted with $10 \mathrm{~g}$ of inert, nonporous $\alpha-\mathrm{Al}_{2} \mathrm{O}_{3}$ powder (Sigma-Aldrich, 100-200 mesh, $\geqslant 99 \%$ ) and loaded into the reactor in the glovebox. The feed partial pressures were 100 mbar of ethylene, $400 \mathrm{mbar}^{\circ} \mathrm{H}_{2}$, and 700 mbar of helium, with a total flow rate of 100 $\mathrm{mL}(\mathrm{NTP}) / \mathrm{min}$. Products were analyzed with an on-line Agilent 6890 gas chromatograph. The ethylene conver-

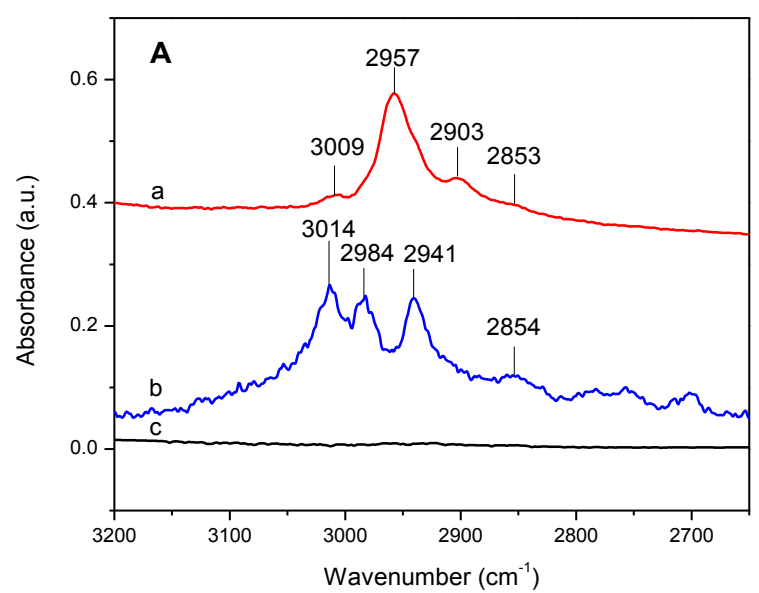

sions were $<5 \%$ and shown to be well approximated as differential, determining reaction rates directly. Rates are expressed as turnover frequencies (TOF), defined as the number of mols of ethylene converted per total Rh atom per second; the TOF data are based on conversions to the product ethane.

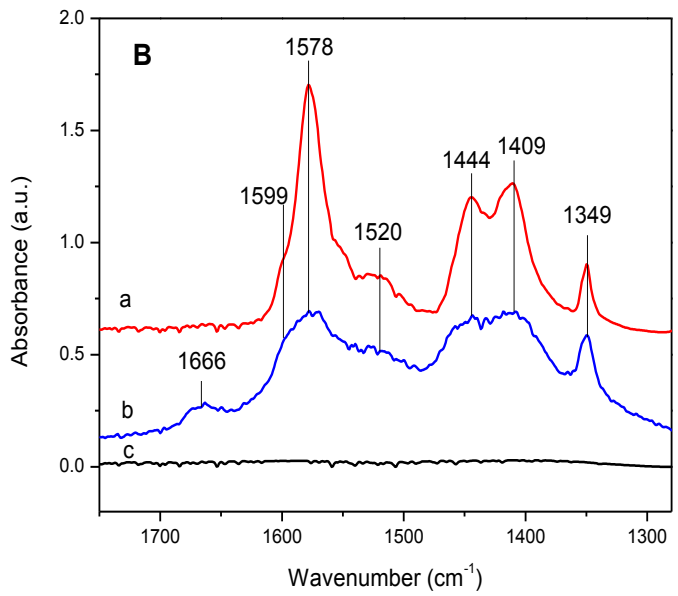

Figure 1. IR spectra in $(\mathrm{A})$ the $v_{\mathrm{C}-\mathrm{H}}$ region and (B) in the $v_{\mathrm{CO}}$ region of $1280-1750 \mathrm{~cm}^{-1}$ characterizing the samples (a) formed by the reaction of $\mathrm{MgO}$ (calcined at $973 \mathrm{~K}$ ) with $\mathrm{Rh}_{2}(\mathrm{OAc})_{4}$ in $n$-pentane solvent after removal of the solvent, (b) $\mathrm{Rh}_{2}(\mathrm{OAc})_{4}$ in $\mathrm{KBr}$ mull, and (c) $\mathrm{MgO}$ (calcined at $973 \mathrm{~K}$ ).

Table 1. Frequencies of IR bands $\left(\mathrm{cm}^{-1}\right)$ observed in the $v_{\mathrm{CH}}$ region and in the $v_{\mathrm{CO}}$ region of $1280-1750 \mathrm{~cm}^{-1}$, characterizing reference compounds and sample formed by adsorption of $\mathrm{Rh}_{2}(\mathrm{OAc})_{4}$ on $\mathrm{MgO}$ that was highly dehydroxylated by calcination at $973 \mathrm{~K}$

\begin{tabular}{|c|c|c|c|c|c|}
\hline \multicolumn{3}{|c|}{ Sample } & \multicolumn{2}{|c|}{ Sample } & \multirow[t]{2}{*}{ Assignment } \\
\hline $\mathrm{Rh}_{2}(\mathrm{OAc})_{4}$ & $\begin{array}{l}\text { Species formed } \\
\mathrm{MgO}\end{array}$ & from $\mathrm{Rh}_{2}(\mathrm{OAc})_{4}$ on & $\mathrm{Na}(\mathrm{OAc})_{2}[2 \mathrm{O}]$ & $\mathrm{HOAc} / \mathrm{MgO}[21,22]$ & \\
\hline 3014 & & 3009 & 3010 & 3014 & $v(\mathrm{C}-\mathrm{H})$ \\
\hline 2984 & & 2957 & 2981 & & $v(\mathrm{C}-\mathrm{H})$ \\
\hline 2941 & & 2903 & 2935 & 2937 & $v(\mathrm{C}-\mathrm{H})$ \\
\hline 2854 & & 2853 & & & \\
\hline & & & & 1701 & $v(\mathrm{C}=\mathrm{O})$ dimer \\
\hline 1666 & & & 1693 & 1653 & $v(C=O)$ chain form \\
\hline 1599 & & 1599 & & & \\
\hline 1578 & & 1578 & 1556 & 1570 & $v(C-O), v(C=O)$ \\
\hline 1520 & & 1520 & & & \\
\hline 1444 & & 1444 & 1429 & 1432 & $\delta_{\mathrm{CH}_{3}}$ \\
\hline 1409 & & 1409 & 1413 & 1416 & $v(\mathrm{C}-\mathrm{O})$, or $\delta_{\mathrm{CH}_{3}}$ \\
\hline 1349 & & 1349 & 1344 & 1364 & $\delta_{\mathrm{CH}_{3}}$, or v $(\mathrm{C}-\mathrm{O})$ \\
\hline
\end{tabular}

\section{Results}

3.1 Characterization of MgO-supported Species Formed from $\mathrm{Rh}_{2}(\mathrm{OAc})_{4}$

IR spectroscopy was used to characterize the adsorption of $\mathrm{Rh}_{2}(\mathrm{OAc})_{4}$ on $\mathrm{MgO}$ that had been calcined at $973 \mathrm{~K}$ to give a high degree of surface dehydroxylation [6]. Spectra in the $v_{\mathrm{OH}}$ region (Figure $\mathrm{S}$, Supporting Information) give evidence of only one peak, at $3747 \mathrm{~cm}^{-1}$, which is assigned to terminal $\mathrm{OH}$ groups on MgO.[23, 24] This band decreased markedly in intensity upon adsorption of
$\mathrm{Rh}_{2}(\mathrm{OAc})_{4}$, indicating the involvement of the support surface $\mathrm{OH}$ groups in the adsorption.

IR spectra characterizing the $\mathrm{Rh}_{2}(\mathrm{OAc})_{4}$ precursor and the sample prepared by its adsorption on the $\mathrm{MgO}$ powder from a solution of $n$-pentane (Figure 1, Table 1) include bands in the $v_{\mathrm{CH}}$ region $\left(3200-2650 \mathrm{~cm}^{-1}\right)$ and the $v_{\mathrm{CO}}$ region representative of the acetate groups $\left(1750-1200 \mathrm{~cm}^{-1}\right)$. Bands characterizing the supported species at 1599, 1578, 1520, 1444, 1409, and $1349 \mathrm{~cm}^{-1}$ nearly match those of $\mathrm{Rh}_{2}(\mathrm{OAc})_{4}$ itself (Figure 1, Table 1), indicating that the 
rhodium retained most of its acetate ligands after adsorption; however, a band at $1666 \mathrm{~cm}^{-1}$ disappeared after the adsorption.

$\mathrm{Xu}$ et al.[21] investigated the IR spectra of $\mathrm{CH}_{3} \mathrm{COOH}$ adsorbed on $\mathrm{MgO}$. Two bands arose upon adsorption, at 1701 and $1653 \mathrm{~cm}^{-1}$, which have been assigned to $v_{\mathrm{C}=\mathrm{O}}$ vibrations of $\mathrm{OAc}^{-}$in dimeric or oligomeric forms. These chain structures are formed by hydrogen bonding involving $\mathrm{CH}_{3}$ and $\mathrm{COO}^{-}$groups. Ma et al. [22] reported a band at 1710 $\mathrm{cm}^{-1}$ when they performed a similar experiment with $\mathrm{CH}_{3} \mathrm{COOH}$ adsorbed on $\mathrm{MgO}$. Ito et al. [20] reported the IR spectrum of $\mathrm{Na}(\mathrm{OAc})_{2}$, including a band at $1693 \mathrm{~cm}^{-1}$. Similar hydrogen bonding between dirhodium acetate moieties is suggested to occur in the solid precursor, so that the molecules are linked in a hydrogen-bonded chain [25]. We suggest that the $1666-\mathrm{cm}^{-1}$ band be assigned to $v_{\mathrm{C}=\mathrm{O}}$ of the chain-connected moieties and thus infer that the hydrogen-bonded chains broke upon adsorption.

The bands characterizing $\mathrm{Rh}_{2}(\mathrm{OAc})_{4}$ at 3014, 2984, and $2941 \mathrm{~cm}^{-1}$ are assigned to the $\mathrm{C}-\mathrm{H}$ stretching vibrations of $\mathrm{CH}_{3}$ groups in OAc ligands [20], and they all have almost the same intensity. Upon adsorption of the dinuclear rhodium complex on $\mathrm{MgO}$, these bands shifted to 3009, 2957 , and $2903 \mathrm{~cm}^{-1}$, and the $2957-\mathrm{cm}^{-1}$ band became more intense than the other two.

Thus, the IR spectra demonstrate that the precursor was chemisorbed and well dispersed on the MgO surface; the shifts in the bands resulting from adsorption are consistent with the suggestion that the rhodium acetate moieties might have been distorted by interactions with the $\mathrm{MgO}$. However, the IR spectra are not sufficient to determine the surface structures, and in particular they do not determine whether any of the acetate ligands were dissociated from the rhodium.

Table 2. EXAFS fit parameters ${ }^{a}$ at the Rh K edge characterizing $\mathrm{MgO}$-supported rhodium dimer formed by chemisorption of $\mathrm{Rh}_{2}(\mathrm{OAc})_{4}^{b}$

\begin{tabular}{ccccc}
\hline Shell & $N$ & $R(\AA)$ & $10^{3} \times \Delta \sigma^{2}\left(\AA^{2}\right)$ & $\Delta E_{\mathrm{o}}(\mathrm{eV})$ \\
\hline $\mathrm{Rh}-\mathrm{O}_{\mathrm{s}}$ & 3.95 & 2.05 & 8.2 & -3.41 \\
$\mathrm{Rh}-\mathrm{Rh}$ & 1.04 & 2.39 & 4.85 & -3.54 \\
$\mathrm{Rh}-\mathrm{O}_{\text {long }}$ & 3.95 & 2.74 & 3.30 & 7.9 \\
$\mathrm{Rh}-\mathrm{C}_{\mathrm{s}}$ & 3.05 & 3.20 & 1.85 & -8.0 \\
$\mathrm{Rh}-\mathrm{Mg}$ & 3.50 & 3.88 & 9.8 & 4.02 \\
$\mathrm{Rh}-\mathrm{C}_{\text {long }}$ & 3.05 & 4.58 & 0.78 & -7.4 \\
\hline
\end{tabular}

${ }^{a}$ Notation: $N$, coordination number; $R$, distance between absorber and backscatterer atoms; $\Delta \sigma^{2}$, disorder term; $\Delta E_{\mathrm{o}}$, inner potential correction; the subscripts s and l refer to short and long, respectively. ${ }^{b}$ Ranges used in EXAFS analysis: wave number, $k, 4.27^{-13.52} \AA^{-1} ; \quad R, 0^{-} 5 \AA$. Error bounds (accuracies) characterizing the structure parameters estimated to be $N, \pm 10 \% ; R, \pm 0.02 \AA ; \Delta \sigma^{2}, \pm 20 \% ; \Delta E_{0}$, $\pm 20 \%$, but these values do not pertain to the Rh-Mg and $\mathrm{Rh}-\mathrm{C}_{\text {long }}$ contributions, for which the errors are greater.
The goodness of fit is 4.1 and the fitting method is described in the Supporting Information.

Further evidence of the supported species is provided by the EXAFS data. The Rh-Rh coordination number of nearly 1 demonstrates that the rhodium pairs did not split upon bonding to the $\mathrm{MgO}$. When fitting the rhodium edge data, we considered the near-neighbor oxygen atoms in acetate ligands and on the support surface to be in the same shell because fitting showed that the data are not sufficient to resolve them. The $\mathrm{Rh}-\mathrm{O}_{\mathrm{s}}$ (the subscript refers to short) coordination number of nearly 4 and the $\mathrm{Rh}-\mathrm{C}_{\mathrm{s}}$ coordination number of nearly 3 characterizing the species formed by chemisorption of $\mathrm{Rh}_{2}(\mathrm{OAc})_{4}$ are consistent with the inference that the rhodium complex bonded to $\mathrm{MgO}$ with the loss of one acetate ligand, to form supported $\mathrm{Rh}_{2}(\mathrm{OAc})_{3}$ species, with each $\mathrm{Rh}$ atom in the resultant surface species bonded, on average, to one oxygen atom of the support.

The average $\mathrm{Rh}-\mathrm{Rh}$ distance determined by the EXAFS data of the species formed by chemisorption of $\mathrm{Rh}_{2}(\mathrm{OAc})_{4}$ is $2.39 \AA$, which matches the $\mathrm{Rh}-\mathrm{Rh}$ distance in the $\mathrm{Rh}_{2}(\mathrm{OAc})_{4}$ precursor determined by the crystal structure.[26]. Thus, the chemisorption did not change the Rh-Rh distance, but this comparison is not sufficient to determine whether the Rh-Rh bond was intact. We emphasize that the distance is shorter than a $\mathrm{Rh}-\mathrm{Rh}$ bonding distance in the $\mathrm{MgO}$-supported rhodium dimer formed by treating supported $\mathrm{Rh}\left(\mathrm{C}_{2} \mathrm{H}_{4}\right)_{2}$ in $\mathrm{H}_{2}$ at $353 \mathrm{~K}$ for $1 \mathrm{~h}(2.71 \AA \AA)$ [8].

The EXAFS Rh-Mg shell and the Rh-C shells with the longer $\mathrm{Rh}-\mathrm{C}$ distances are characterized by larger errors than the other shells, and we infer that the surface species may not constitute a uniform array.

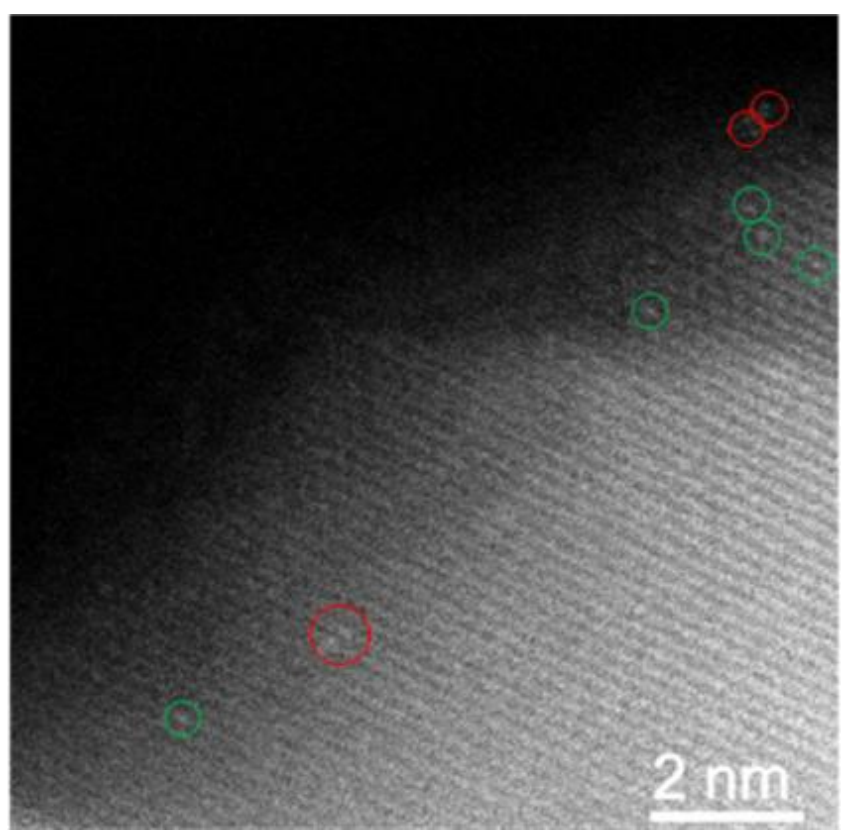


Figure 2. STEM image showing rhodium pair sites in MgO-supported sample prepared by chemisorption of $\mathrm{Rh}_{2}(\mathrm{OAc})_{4}$; pair sites are circled in red and isolated $\mathrm{Rh}$ atoms are circled in green.

STEM images of the supported sample (Figure 2 and Figure S2, Supporting Information) confirm the presence of rhodium pairs and show that they are well separated from each other. The average $\mathrm{Rh}-\mathrm{Rh}$ distance determined by analysis of the images $2.4 \AA$, is in good agreement with the EXAFS data (Table 2).

Successive images give evidence of beam damagedemonstrating the movement of $\mathrm{Rh}$ atoms that were initially present in pairs. The data are consistent with the premise that the Rh atoms initially were all present in pairs, but the early onset of beam damage-which we infer took place so fast that it was not possible to record images of unperturbed rhodium pair sites. Such beam damage is expected, as illustrated, for example, by observations of triosmium species on the same support [27, 28].

We emphasize that imaging of isolated $\mathrm{Rh}$ atoms on the support is challenging because of the relatively poor Zcontrast between $\mathrm{Rh}$ atoms and the support and the brightness of columns of $\mathrm{Mg}$ atoms in thick zones of $\mathrm{MgO}$ particles. Consequently, we were able to identify $\mathrm{Rh}$ atoms only at the edges of $\mathrm{MgO}$ particles. We know of only a few other examples of images of Rh atoms on supports $[29,30]$. The STEM image of Figure 2 is the first of supported rhodium pair sites.

\subsection{Reactivity of Supported Rhodium Pair Sites}

To test the reactivity of the supported rhodium pair sites formed initially, the original supported sample was brought in contact with flowing $\mathrm{CO}$ at $298 \mathrm{~K}$ and $\mathrm{s}$ bar for 2 min. A sharp $v_{\mathrm{CO}}$ band appeared immediately in the IR spectrum, at $2117 \mathrm{~cm}^{-1}$, indicating the formation of a rhodium monocarbonyl species (Figure 3). No changes were observed in the $\mathrm{C}-\mathrm{H}$ region of the spectrum or in the region characterizing the OAc groups $\left(1750-1200 \mathrm{~cm}^{-1}\right)$, suggesting that $\mathrm{CO}$ did not replace OAc ligands. The sharpness of the $v_{\mathrm{CO}}$ band (with a full width at half-maximum (fwhm) of $10 \mathrm{~cm}^{-1}$ ) indicates a high degree of uniformity of the rhodium carbonyl species and, we infer, their surfacebound precursors.

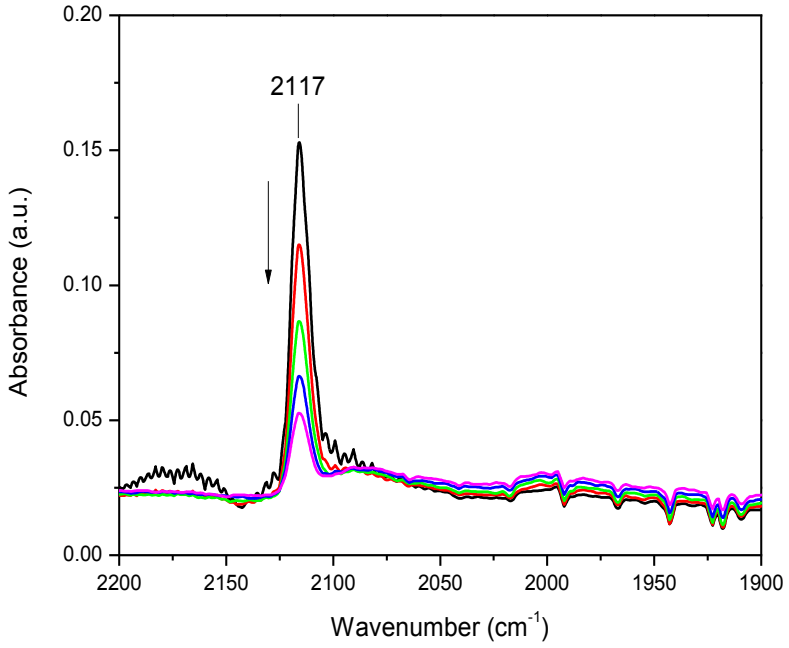

Figure 3. IR spectra of the sample formed by bringing $\mathrm{CO}$ in contact with the $\mathrm{MgO}$-supported species formed from $\mathrm{Rh}_{2}(\mathrm{OAc})_{4}$ for $2 \mathrm{~min}$ at $298 \mathrm{~K}$, followed by flowing helium for 2 (black line), 4 (red), 6 (green), 8 (blue), and $10 \mathrm{~min}$ (pink). The full width at half maximum (fwhm) of the CO bands is approximately $11 \mathrm{~cm}^{-1}$.

When the gas flowing over the sample was switched to helium, the new $v_{\mathrm{CO}}$ band gradually (within $10 \mathrm{~min}$ ) decreased in intensity. Its intensity was completely recovered when the sample was exposed to a pulse of $\mathrm{CO}$ in helium (8o molecules of CO per Rh atom). These observations indicate that the bonding of $\mathrm{CO}$ to the rhodium species was reversible. An experiment with ${ }^{13} \mathrm{CO}$ confirmed the identification of this new band as a carbonyl band (Figure $\mathrm{S}_{3}$, Supporting Information).

We also investigated the reaction of $\mathrm{CO}$ with the $\mathrm{Rh}_{2}(\mathrm{OAc})_{4}$ precursor under similar conditions (the precursor was diluted with $\mathrm{KBr}$ and pressed into a wafer). A single band appeared in the IR spectrum at $2095 \mathrm{~cm}^{-1}$ when the precursor was brought in contact with flowing $\mathrm{CO}$ at $298 \mathrm{~K}$ and 1 bar for $2 \mathrm{~min}$, and it remained when the $\mathrm{CO}$ in the gas stream was replaced by helium. The single carbonyl band indicates only one type of bonding site for a $\mathrm{CO}$ ligand on the precursor $\mathrm{Rh}_{2}(\mathrm{OAc})_{4}$. Evidence of the identity of this bonding site is suggested by the crystal structure of $\mathrm{Rh}_{2}(\mathrm{OAc})_{4}[26,31]$; two $\mathrm{Rh}$ atoms are surrounded by four acetate ligands in a paddle-wheel structure, and each Rh atom has one axial open coordination site where reactants can bond, leading to catalysis of a family of reactions in solution [32-35]. Thus, we suggest that $\mathrm{CO}$ bonds terminally to axial open sites on the $\mathrm{Rh}_{2}(\mathrm{OAc})_{4}$ precursor.

Correspondingly, we observed that the supported species approximated as $\mathrm{Rh}_{2}(\mathrm{OAc})_{3}$ that formed as a result of the reaction of the $\mathrm{Rh}_{2}(\mathrm{OAc})_{4}$ with $\mathrm{MgO}$ retained open sites like those on $\mathrm{Rh}_{2}(\mathrm{OAc})_{4}$, as evidenced by the single carbonyl band at $2117 \mathrm{~cm}^{-1}$ that appeared in the spectrum of the supported sample when it was brought in contact with a pulse of $\mathrm{CO}$ (8o $\mathrm{CO}$ molecules per Rh atom) at 298 
$\mathrm{K}$. The difference in frequencies of the $v_{\mathrm{CO}}$ bands in the molecular and supported species suggests a significant interaction between the supported species and the support. Although the carbonyl ligands that were bonded to the $\mathrm{Rh}_{2}(\mathrm{OAc})_{4}$ precursor were stable in flowing helium at 298 K (Figure S4, Supplementary Material), those on the supported species were not.

Carbonyl band frequencies are indicators of the oxidation states of metals. The $2117-\mathrm{cm}^{-1}$ band characterizing the CO ligands bonded on the supported rhodium species represented as $\mathrm{Rh}_{2}(\mathrm{OAc})_{3}$ is close to that identified with $\mathrm{Rh}^{2+}$ on $\gamma-\mathrm{Al}_{2} \mathrm{O}_{3}$, at $2120 \mathrm{~cm}^{-1}[36,37]$, suggesting that rhodium was present in the supported species as $\mathrm{Rh}(\mathrm{II})$. Because the oxidation state of rhodium in $\mathrm{Rh}_{2}(\mathrm{OAc})_{4}$ is also 2+, we suggest that the rhodium did not undergo a change in oxidation state upon chemisorption on $\mathrm{MgO}$.

When the MgO-supported rhodium species was exposed to a second pulse of $\mathrm{CO}$ in flowing helium at $298 \mathrm{~K}$ (8o $\mathrm{CO}$ molecules per $\mathrm{Rh}$ atom) (Figure $\mathrm{S}_{5}$, Supporting Information), two weak bands appeared in the IR spectrum, at 2083 and $2004 \mathrm{~cm}^{-1}$. These are assigned to $\mathrm{MgO}$ supported rhodium gem-dicarbonyls, $\mathrm{Rh}^{+}(\mathrm{CO})_{2}$, and their appearance and intensities suggest that a small fraction of the rhodium pair sites were fragmented by $\mathrm{CO}$ at $298 \mathrm{~K}$. These results are consistent with the results of Asakura et al. [38], who showed by IR spectroscopy that the rhodium dimer in $\mathrm{SiO}_{2}$-supported trans- $\left[\mathrm{Rh}\left(\mathrm{C}_{5} \mathrm{Me}_{5}\right)\left(\mathrm{CH}_{3}\right)\right]_{2}(\mu-$ $\left.\mathrm{CH}_{2}\right)_{2}$ ] is dissociated in the presence of flowing $\mathrm{CO}$ at 313 $\mathrm{K}$. It has been reported [39] that rhodium clusters supported on an acidic support, dealuminated HY zeolite, are readily converted into site-isolated rhodium species when exposed to a pulse of $\mathrm{CO}$ at $298 \mathrm{~K}-\mathrm{a}$ process that is much faster than what we observed for our rhodium species on the basic MgO support.

\subsection{Fragmentation of Supported Rhodium Pairs during Treatments in Various Gases}

When the supported species were treated in continuously flowing $\mathrm{CO}$ at $393 \mathrm{~K}$ and 1 bar, IR spectra recorded during the changes (Figure 4) demonstrate a decreasing intensity of the bands characterizing the carbonyl band at $2117 \mathrm{~cm}^{-1}$ and a simultaneous increase in intensity of the bands at 2083 and $2004 \mathrm{~cm}^{-1}$ that indicate rhodium gemdicarbonyls. Thus, the spectra of Figure 4 demonstrate that acetate ligands were replaced by $\mathrm{CO}$ as the rhodium pairs fragmented. A band at $1892 \mathrm{~cm}^{-1}$, assigned to $\mathrm{CO}$ ligands bridging $\mathrm{Rh}$ atoms [40], appeared during the treatment, which we infer to be indicative of an intermediate formed as the pairs were broken. After $2 \mathrm{~h}$ in flowing $\mathrm{CO}$, the areas of the IR bands indicate that approximately $95 \%$ of the pairs had been broken, forming rhodium gem-dicarbonyls.

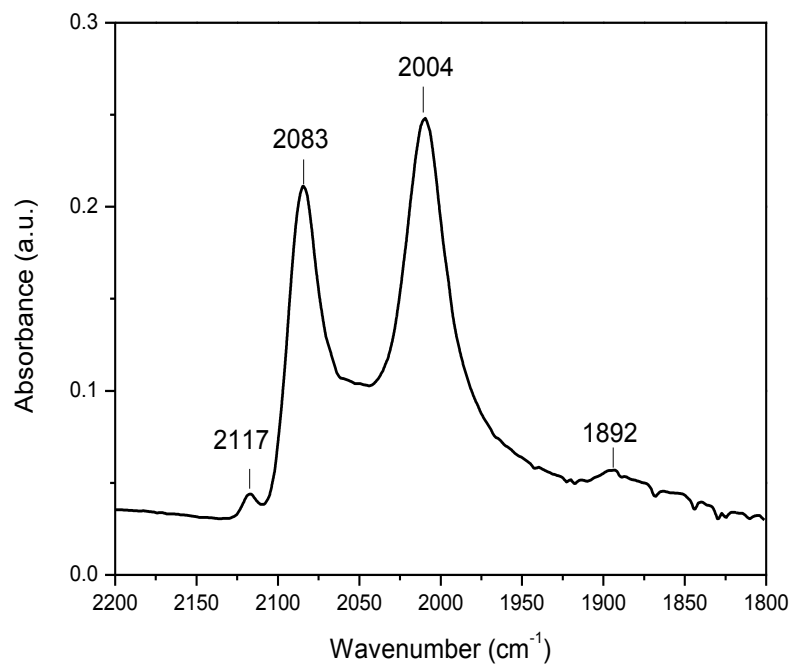

Figure 4. IR spectrum of sample formed by bringing a steadily flowing stream of $\mathrm{CO}$ at 1 bar in contact with the MgO-supported $\mathrm{Rh}_{2}(\mathrm{OAc})_{4}$ at $393 \mathrm{~K}$ for $2 \mathrm{~h}$.

The reactions of the $\mathrm{MgO}$-supported species derived from $\mathrm{Rh}_{2}(\mathrm{OAc})_{4}$ in various flowing gases other than $\mathrm{CO}$ were also tested, with the changes again monitored by IR spectroscopy. The temperature was typically 353 or $393 \mathrm{~K}$. Treatment of the supported species formed from $\mathrm{Rh}_{2}(\mathrm{OAc})_{4}$ with flowing ethylene at $393 \mathrm{~K}$ and 1 bar led to break-up of the pairs as well. New bands appeared in both the $\mathrm{C}-\mathrm{H}\left(3061\right.$ and $\left.3000 \mathrm{~cm}^{-1}\right)$ and $\mathrm{C}-\mathrm{O}$ regions $(2008 \mathrm{~cm}$ $\left.{ }^{1}\right)$ (Figure 5). The former match the bands characterizing $\pi$-bonded ethylene in mononuclear rhodium complexes $[10,40]$. The spectra thus indicate the formation of $\mathrm{Rh}\left(\mathrm{C}_{2} \mathrm{H}_{4}\right)(\mathrm{CO})$ species, consistent with what has been observed in the reaction of ethylene with rhodium gemdicarbonyls on this support at $298 \mathrm{~K}$ [41]. We suggest that the $\mathrm{CO}$ ligands in $\mathrm{Rh}\left(\mathrm{C}_{2} \mathrm{H}_{4}\right)(\mathrm{CO})$ species were generated by the decomposition of acetate ligands at $393 \mathrm{~K}$.

After the treatment with flowing ethylene, the temperature was decreased to $298 \mathrm{~K}$, and the resultant surface species were probed with a pulse of $\mathrm{CO}$ (8o molecules per $\mathrm{Rh}$ atom). The IR spectra (Figure 5) demonstrate the disappearance of the bands associated with $\pi$-bonded ethylene ligands (at 3061 and $3000 \mathrm{~cm}^{-1}[40]$ ), accompanied by the nearly instantaneous formation of two bands assigned to rhodium gem-dicarbonyls (2083 and $2004 \mathrm{~cm}^{-1}$ [42]). The facile replacement of ethylene ligands by $\mathrm{CO}$ is consistent with earlier results [10, 40]. The IR band areas indicate that approximately $55 \%$ of the rhodium species were fragmented to give site-isolated rhodium species as a result of the treatment with ethylene at $398 \mathrm{~K}$ for $2 \mathrm{~h}-$ and this conversion is much less than that observed when $\mathrm{CO}$ was the reactant instead of ethylene, indicating that $\mathrm{CO}$ is more effective in breaking up the pair sites than ethylene, consistent with the stronger bonding of $\mathrm{CO}$ than of ethylene to the rhodium centers. 
The 1892 - and $1854^{-\mathrm{cm}^{-1}}$ bands, assigned to CO ligands bridging Rh atoms (Figure 5), further indicate an intermediate formed as the fragmentation took place.
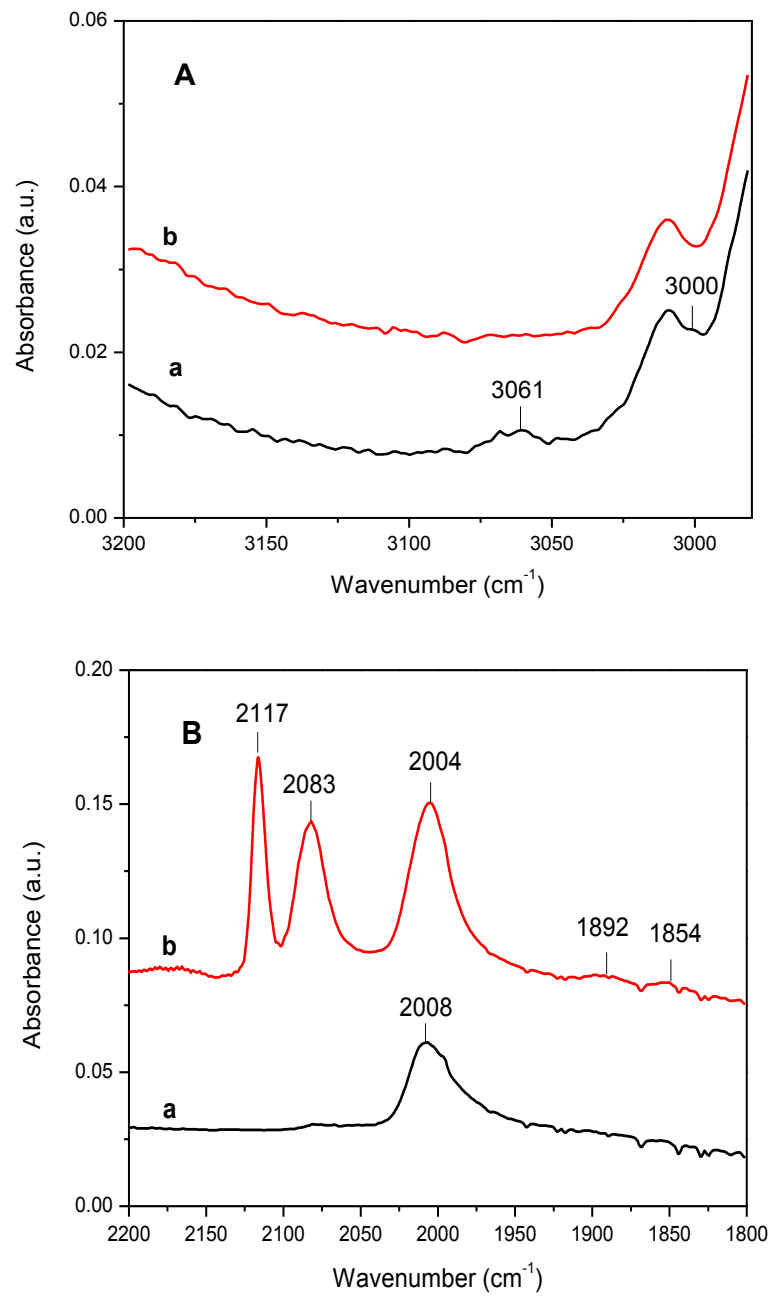

Figure 5. IR spectra in (A) $\mathrm{C}-\mathrm{H}$ stretching region and (B) $\mathrm{C}-\mathrm{O}$ stretching region of the sample formed by (a) bringing ethylene in contact with the $\mathrm{MgO}$-supported sample formed from $\mathrm{Rh}_{2}(\mathrm{OAc})_{4}$ at $393 \mathrm{~K}$ for $2 \mathrm{~h}$, then (b) flowing $\mathrm{CO}$ for $2 \mathrm{~min}$ and helium for $5 \mathrm{~min}$ at $298 \mathrm{~K}$.

When $\mathrm{H}_{2}$ was brought in contact with the supported species initially formed from $\mathrm{Rh}_{2}(\mathrm{OAc})_{4}$ at $353 \mathrm{~K}$, the acetate bands gradually decreased in intensity. No rhodium hydride band was evident in the IR spectrum during the treatment (but these bands are typically low in intensity, and the absence of such a peak is not sufficient evidence to rule out the possible formation of rhodium hydride species). Then the sample was probed with a pulse of $\mathrm{CO}$ at $298 \mathrm{~K}$ (1 CO molecule per Rh atom). The IR spectra demonstrate a series of new bands growing in, at 2078, 2032, 2002, 1959, 1892, and $1854 \mathrm{~cm}^{-1}$ (Figure 6). These are all assigned, on the basis of reported data $[8,40]$, to $\mathrm{Rh}_{2}(\mathrm{CO})_{6}$ species (the oxidation states of rhodium is less than +1$)$. Thus, the spectra indicate that acetate ligands on the initial species formed from $\mathrm{Rh}_{2}(\mathrm{OAc})_{4}$ are removed by $\mathrm{H}_{2}$ at $353 \mathrm{~K}$, apparently reducing the rhodium without changing the rhodium nuclearity. We infer that a paired rhodium species without acetate ligands is an intermediate when the fragmentation takes place in $\mathrm{CO}$ or ethylene.

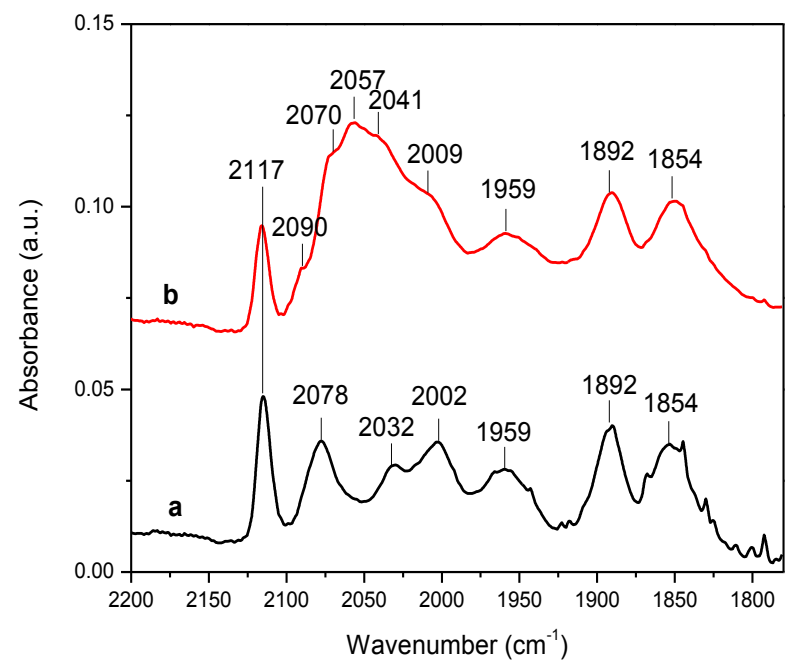

Figure 6. IR spectrum of the sample formed by bringing $\mathrm{H}_{2}$ in contact with the $\mathrm{MgO}$-supported $\mathrm{Rh}_{2}(\mathrm{OAc})_{4}$ at (a) $353 \mathrm{~K}$ and (b) $393 \mathrm{~K}$ for $2 \mathrm{~h}$, then flowing $\mathrm{CO}$ for $2 \mathrm{~min}$ and helium for $5 \mathrm{~min}$ at room temperature.

Table 3. Structure changes of $\mathrm{MgO}$-supported species formed from supported species inferred to be $\mathrm{Rh}_{2}(\mathrm{OAc})_{3}$ in various reactive atmospheres.

\begin{tabular}{|c|c|c|c|c|}
\hline $\begin{array}{l}\text { Treat- } \\
\text { ment } \\
\text { gas }\end{array}$ & $\begin{array}{l}\text { Tem- } \\
\text { pera- } \\
\text { ture, } \mathrm{K}\end{array}$ & $\begin{array}{c}\text { Time, } \\
\mathrm{h}\end{array}$ & $\begin{array}{l}\text { Species formed } \\
\text { after treatment }\end{array}$ & $\begin{array}{c}\text { Approx- } \\
\text { imate per- } \\
\text { centage of } \\
\text { rhodium } \\
\text { species } \\
\text { formed } \\
\text { from } \\
\mathrm{Rh}_{2}\left(\mathrm{OAc}_{a}\right.\end{array}$ \\
\hline $\mathrm{CO}$ & 393 & 2 & $\mathrm{Rh}(\mathrm{CO})_{2}$ & 94 \\
\hline ethylene & 393 & 2 & $\mathrm{Rh}\left(\mathrm{C}_{2} \mathrm{H}_{4}\right)(\mathrm{CO})$ & 42 \\
\hline \multirow[t]{2}{*}{$\mathrm{H}_{2}$} & 353 & 2 & $\begin{array}{l}\mathrm{Rh}_{2} \text { with unde- } \\
\text { termined ligands }\end{array}$ & $5^{1}$ \\
\hline & 393 & 2 & $\begin{array}{c}\mathrm{Rh}_{2}, \mathrm{Rh}_{4}, \mathrm{Rh}_{6} \\
\text { with various } \\
\text { ligands }\end{array}$ & 66 \\
\hline helium & 393 & 2 & $\mathrm{Rh}_{1}$ & 5 \\
\hline
\end{tabular}

${ }^{a}$ Conversions were estimated on the basis of changes in the area of the $2117-\mathrm{cm}^{-1}$ band.

When this sample was still in the presence of $\mathrm{H}_{2}$ at the higher temperature of $398 \mathrm{~K}$, the spectrum after introduction of a pulse of $\mathrm{CO}$ indicates mixed rhodium species, suggested by the spectra to include carbonyls of $\mathrm{Rh}_{2}$ (1959, 1892 and $\left.1854 \mathrm{~cm}^{-1}\right)$ [8, 40], $\mathrm{Rh}_{4}\left(2070,2057 \mathrm{~cm}^{-1}\right)$ 
[43-45], and $\mathrm{Rh}_{6}\left(2090,2070,2041,2009 \mathrm{~cm}^{-1}\right)$ [15, 44, 46]-thus, aggregation of the rhodium into larger clusters. The conversion after $2 \mathrm{~h}$ at $393 \mathrm{~K}$ is estimated on the basis of the IR band intensities to be approximately $66 \%$.

The stability of the supported species originally formed from $\mathrm{Rh}_{2}(\mathrm{OAc})_{4}$ at $393 \mathrm{~K}$ in flowing helium was also characterized by IR spectroscopy. The data of Figure S6 in Supporting Information show that about $5 \%$ of the paired species were fragmented to give mononuclear rhodium species, accompanied by a decrease in intensity of the acetate bands, indicating the decomposition of acetate. The data suggest that the break-up of the rhodium pairs was caused in part by self-induced decomposition involving reaction with ligand-derived species.

The changes in the structure of the supported rhodium species under various reactive atmospheres are summarized in Table 3. The tendency of the rhodium pairs to fragment in the various gases increased in the order helium $<$ ethylene $<$ CO.

\subsection{Rates of Ethylene Hydrogenation Catalysis}

The catalyst in the initially prepared form was tested for ethylene hydrogenation in a tubular plug-flow reactor at $298 \mathrm{~K}$ and 1 bar. The feed component partial pressures were 100 mbar of ethylene, $400 \mathrm{mbar}^{\circ} \mathrm{H}_{2}$, and $500 \mathrm{mbar}$ of helium; details are given in the caption of Figure 7 . Conversions in the range of $1-5 \%$ were measured, and the data were extrapolated to zero time on stream. The extrapolated conversions were found to be in the differential range, determining reaction rates directly, and these are reported as turnover frequencies (TOF), with the normalization being per total Rh atom. There was no detectable activity in the absence of the catalyst, and the MgO support alone was inactive. Therefore, we infer that catalytic activity is attributable to the rhodium species on $\mathrm{MgO}$.

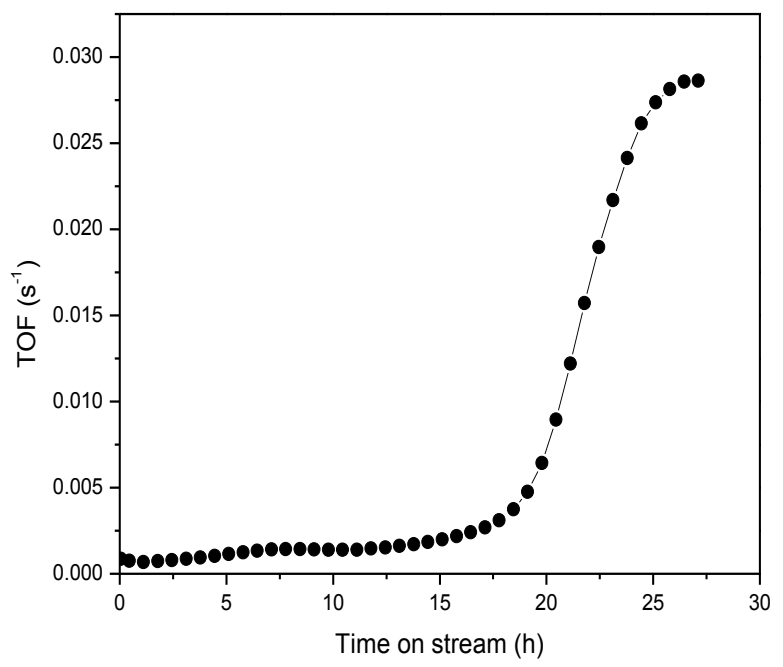

Figure 7. Increasing rate of ethylene hydrogenation catalysis in a once-through flow reactor catalyzed by sample formed by chemisorption of $\mathrm{Rh}_{2}(\mathrm{OAc})_{4}$ on $\mathrm{MgO}$ (reaction conditions: $298 \mathrm{~K}, 1$ bar; total gas feed flow rate, 100 $\mathrm{ml} / \mathrm{min}$; feed component partial pressures: 100 mbar of ethylene, 400 mbar of $\mathrm{H}_{2}, 500$ mbar of helium; catalyst mass, $100 \mathrm{mg}$ )

The initial TOF was found to be $(9.2 \pm 0.1) \times 10^{-4} \mathrm{~s}^{-1}$. This activity is much less than that of the MgO-supported single-site rhodium diethylene complexes or supported rhodium ethyl complexes that were formed by treating supported rhodium diethylene complexes, synthesized as stated above, in $\mathrm{H}_{2}$ at $353 \mathrm{~K}$ for $1 \mathrm{~h}$ [40]. The initial TOF values characterizing these species under the same conditions were observed to be $1.9 \times 10^{-2}$ and $1.1 \mathrm{~s}^{-1}$, respectively [40].

The activity of the supported catalyst formed from $\mathrm{Rh}_{2}(\mathrm{OAc})_{4}$ is three orders of magnitude lower than that of $\mathrm{Rh}_{2}$ species without acetate ligands and one order of magnitude lower than that of mononuclear rhodium complexes initially incorporating ethylene ligands. The results indicate that the activity of rhodium species is strongly influenced by both ligands on the metal, which can be inhibitors, and the nuclearity of the metal species. The ligands $\mathrm{C}_{2} \mathrm{H}_{4}$ or $\mathrm{C}_{2} \mathrm{H}_{5}$ on rhodium in either form are inferred not to markedly block the bonding of reactants in catalytic hydrogenation of ethylene, as both of these ligands react with hydrogen to form ethane [11]. However, the acetate ligands on $\mathrm{Rh}_{2}$ are evidently essentially just inhibitors, being difficult to remove in the presence of $\mathrm{H}_{2}$ or ethylene at $298 \mathrm{~K}$ and 1 bar.

The activity of the catalyst initially incorporating the rhodium pairs increased slowly during the first $15 \mathrm{~h}$ on stream and much more rapidly in the following $12 \mathrm{~h}$ (Figure 7 ). The TOF for ethylene hydrogenation reached a value of $0.028 \mathrm{~s}^{-1}$ after $27 \mathrm{~h}$ on stream.

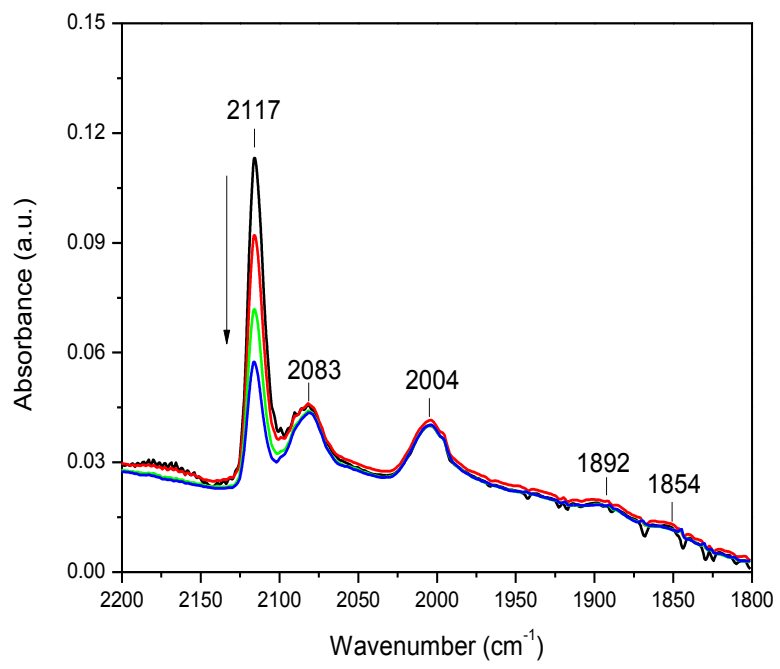

Figure 8. IR spectrum characterizing the catalyst formed from $\mathrm{Rh}_{2}(\mathrm{OAc})_{4}$ on $\mathrm{MgO}$ after ethylene hydrogenation catalysis (at $298 \mathrm{~K}, 1$ bar; total gas feed flow rate, 100 $\mathrm{ml} / \mathrm{min}$; feed component partial pressure, 100 mbar of 
$\mathrm{C}_{2} \mathrm{H}_{4}, 400$ mbar of $\mathrm{H}_{2}, 500$ mbar of He, mass of catalyst, $100 \mathrm{mg}$ ) for $27 \mathrm{~h}$ in an IR cell after flow of $\mathrm{CO}$ for $3 \mathrm{~min}$ followed by helium for 2 (black line), 4 (red), 6 (green) and $10 \mathrm{~min}$ (blue). The spectra indicate the breakup of rhodium pairs into single rhodium sites during ethylene hydrogenation catalysis.

In an attempt to understand the changes in catalyst performance during operation, we characterized the working catalysts by IR spectroscopy. The catalyst initially incorporating the rhodium pairs (Figure 3) was treated under the aforementioned conditions of catalytic ethylene hydrogenation. After $27 \mathrm{~h}, \mathrm{CO}$ again was used as before to probe the rhodium species, now of the used catalyst. The spectra of Figure 8 show that the rhodium pairs had been fragmented, and treatment of the fragmented species gave rhodium gem-dicarbonyls. About $10 \%$ of the initial pair species had been fragmented into mononuclear rhodium complexes after $27 \mathrm{~h}$ of catalytic reaction, as indicated by the intensities of the $2083-$ and $2004-\mathrm{cm}^{-1}$ peaks. Furthermore, two small bands, at 1892 and $1854 \mathrm{~cm}^{-1}$, which have been suggested to represent $\mathrm{Rh}_{2}(\mathrm{CO})_{6}$ species $[8,40]$, also appeared in the spectra, indicating that acetate ligands on the initial species formed from $\mathrm{Rh}_{2}(\mathrm{OAc})_{4}$ were removed without changing the rhodium nuclearity. On the basis of the intensity of the $1892-\mathrm{cm}^{-1}$ band, we infer that about $2 \%$ of the $\mathrm{Rh}_{2}$ species without acetate ligands had formed on the sample after $27 \mathrm{~h}$ reaction. We emphasize that these $\mathrm{Rh}_{2}$ species without acetate ligands are intermediates as the dirhodium species are broken, as discussed above in regard to the $\mathrm{CO}$ and ethylene treatments.

To begin to resolve matters regarding the catalytic species, we estimated the fraction of the catalytic activity associated with each. We assumed as a first approximation that the $\mathrm{Rh}_{2}$ and $\mathrm{Rh}_{1}$ species formed during the fragmentation of the initial supported rhodium species in the 27-h period of catalyst operation are at least approximately characterized by the same initial TOF values observed for catalysts initially in the form of $\mathrm{Rh}\left(\mathrm{C}_{2} \mathrm{H}_{4}\right)_{2}$ and $\mathrm{Rh}_{2}\left(\mathrm{C}_{2} \mathrm{H}_{5}\right)_{2}$ [40]. The corresponding activities are summarized in Table 4 in relation to the compositions of the three forms of the catalyst estimated on the basis of the IR spectra shown in Figure 8 . The results of Table 4 indicate that almost $90 \%$ of the activity is associated with the approximately $2 \%$ of the rhodium species present as dirhodium species without acetate ligands and that the approximately $88 \%$ of the dirhodium species with acetate ligands contributed only about $3 \%$ of the activity. The calculated total TOF based on the approximate initial TOF values of the three species and the composition of the catalyst is $0.025 \mathrm{~s}^{-1}$, close to the experimental TOF of $0.028 \mathrm{~s}^{-1}$. We emphasize that although this comparison is only approximate, the data are sufficient to indicate the importance of the intermediate species acting as the most active species in the catalysis.
Table 4. Activities of various supported rhodium ethylene hydrogenation catalysts ${ }^{a}$

\begin{tabular}{|c|c|c|c|}
\hline $\begin{array}{l}\text { Predomi- } \\
\text { nant } \\
\text { species }^{b}\end{array}$ & $\begin{array}{c}\text { Initial } \\
\text { TOF, } \mathrm{s}^{-1}\end{array}$ & $\begin{array}{l}\text { Approximate } \\
\text { percentage of } \\
\text { this species in } \\
\text { final catalyst, } \\
\qquad(\%)\end{array}$ & $\begin{array}{l}\text { Contribu- } \\
\text { tion of this } \\
\text { species to } \\
\text { the final } \\
\text { TOF (\%) }\end{array}$ \\
\hline $\mathrm{Rh}_{2}(\mathrm{OAc})_{3}$ & $9.2 \times 10^{-4}$ & 88 & 3 \\
\hline $\begin{array}{c}\mathrm{Rh}_{2} \text { with } \\
\text { undeter- } \\
\text { mined } \\
\text { ligands }\end{array}$ & 1.1 & 2 & 90 \\
\hline $\begin{array}{c}\mathrm{Rh}_{1} \text { with } \\
\text { undeter- } \\
\text { mined } \\
\text { ligands }\end{array}$ & $1.9 \times 10^{-2}$ & 10 & 7 \\
\hline
\end{tabular}

${ }^{a}$ The assumptions made to determine these data are stated in the text. ${ }^{b}$ For discussion of the ligands on the rhodium, see the text.

To provide some understanding of the changes occurring during the period of about $15 \mathrm{~h}$ prior to the rapid catalyst activation shown in Figure 7 , the catalyst initially consisting of the rhodium pair sites (Figure 3) was also treated under the aforementioned conditions of the catalytic ethylene hydrogenation reaction for $15 \mathrm{~h}$; after that period of catalysis, the catalyst was exposed to a pulse of $\mathrm{CO}$ at $298 \mathrm{~K}$, and IR spectra were recorded. The resulting spectra are similar to those characterizing the unused catalyst (Figure 3) and show that a sharp band had appeared at $2117 \mathrm{~cm}^{-1}$ (representing supported $\mathrm{Rh}_{2}(\mathrm{OAc})_{3}$ ) and that bands at 2083, 2004, 1892, and $1854 \mathrm{~cm}^{-1}$ that would have indicated broken-up pairs were absent. These results indicate that the rhodium pairs with their acetate ligands were still largely intact during the first $15 \mathrm{~h}$ of reaction, which explains the low catalytic activity during this period. The subsequent activity increase between 15 and 27 $\mathrm{h}$ is associated with the IR bands observed at 2083, 2004, 1892 , and $1854 \mathrm{~cm}^{-1}$, which give evidence of intermediate fragmented rhodium species, indicated by the former two bands representing mononuclear rhodium dicarbonyls and by the latter two bands representing bridging $\mathrm{CO}$ ligands of rhodium dimers without acetate ligands.

\section{Discussion}

\subsection{Model of Supported Rhodium Pairs}

A structural model of the initially formed $\mathrm{MgO}$-supported rhodium pair sites is shown schematically in Scheme $1 \mathrm{~B}$. This model was inferred on the basis of the following observations: (1) IR spectra in the $v_{\mathrm{OH}}$ region (Figure $\mathrm{S} 1$, Supporting Information) indicating the involvement of support $\mathrm{OH}$ groups in the chemisorption of the precursor $\mathrm{Rh}_{2}(\mathrm{OAc})_{4}$; (2) EXAFS data indicating the loss of approximately one acetate ligand per rhodium dimer as a result of the chemisorption; (3) EXAFS data showing that each 
Rh atom was bonded to approximately four oxygen atoms (which we infer to include three from the three remaining acetate ligands on rhodium after chemisorption and one from the support surface); and (4) EXAFS data showing that each $\mathrm{Rh}$ atom on the support was nearby one $\mathrm{Rh}$ atom, on average.
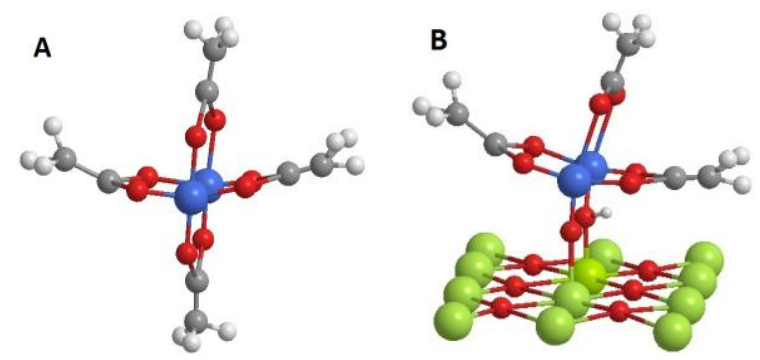

Scheme 1. Structure of (A) $\mathrm{Rh}_{2}(\mathrm{OAc})_{4}$ precursor and (B) simplified structural model of $\mathrm{MgO}$-supported species formed from $\mathrm{Rh}_{2}(\mathrm{OAc})_{4}$ with the loss of one acetate ligand. Red, O; green, Mg; blue, Rh; light gray, C; white, $\mathrm{H}$.

\subsection{Reactions of Metal Carbonyl Clusters with $\mathrm{MgO}$}

Earlier work showed that various metal clusters with carbonyl ligands, exemplified by $\operatorname{Ir}_{4}(\mathrm{CO})_{12}[47,48], \mathrm{Os}_{3}(\mathrm{CO})_{12}$ [49, 50], and $\mathrm{Rh}_{6}(\mathrm{CO})_{16}[15,51]$ react with metal oxides (e.g., $\gamma-\mathrm{Al}_{2} \mathrm{O}_{3}, \mathrm{MgO}$ ) at $298 \mathrm{~K}$ and 1 bar to form almost uniform supported clusters with unchanged nuclearities. Reactions take place between the metal clusters and the support hydroxyl groups, leading to dissociation of one of the carbonyl ligands from the metal cluster, with the cluster then becoming chemisorbed near support $\mathrm{OH}$ groups. These conclusions are based mainly on IR and EXAFS spectra, in some cases complemented by STEM images. Using a smaller cluster as a precursor, Iwasawa's group $[38,52]$ investigated the reaction of the dimer trans$\left[\mathrm{Rh}\left(\mathrm{C}_{5} \mathrm{Me}_{5}\right)\left(\mathrm{CH}_{3}\right)\right]_{2}\left(\mu-\mathrm{CH}_{2}\right)_{2}$ (Me is methyl) with $\mathrm{SiO}_{2}, \gamma-$ $\mathrm{Al}_{2} \mathrm{O}_{3}, \mathrm{TiO}_{2}$, and $\mathrm{MgO}$ ) at $313-373 \mathrm{~K}$ and 1 bar. Their supported species were characterized by IR and EXAFS spectra. The results all indicate that the precursors reacted with $\mathrm{OH}$ groups on the supports, with one of the ligands ( $\mathrm{CO}$ or, in Asakura and Iwasawa's work [38], $\mathrm{C}_{5} \mathrm{Me}_{5}$ ) being removed and the nuclearity of the precursor remaining unchanged.

The results of our work are similar to those of these authors, but with the ligands being simpler than Asakura and Iwasawa's, and, as in their work, we observed a pattern of reaction of the precursor with support $\mathrm{OH}$ groups taking place with dissociation of one of the ligands and retention of the rhodium nuclearity.

The acetate ligands on the rhodium dimers are more readily removed than the CO ligands on the aforementioned metal clusters, and the structure of the species formed from $\mathrm{Rh}_{2}(\mathrm{OAc})_{4}$ is evidently less complex than that of the supported rhodium dimer species reported by Asakura and Iwasawa. This simplicity facilitated the characteriza- tion of changes undergone by our samples under various reaction conditions.

\subsection{Fragmentation of Supported Metal Clusters in Various Atmospheres}

There are reports [53-57] of the fragmentation of supported rhodium clusters and iridium clusters on acidic supports ( $\mathrm{HY}$ zeolite, $\gamma-\mathrm{Al}_{2} \mathrm{O}_{3}$, and $\mathrm{TiO}_{2}$ ) by reaction with either $\mathrm{CO}$ or ethylene at 298 or $353 \mathrm{~K}$. The conversions were interpreted as oxidative fragmentations, because the metals were oxidized (from the formal oxidation state of o in the clusters to +1 after the fragmentation). Surface hydroxyl groups on the supports were inferred to be the oxidizing agents. The fragmentation of metal clusters on these acidic supports takes place under mild conditions, and the processes are fast-for example, supported rhodium clusters on zeolite HY were completely broken up by a pulse of $\mathrm{CO}$ at $298 \mathrm{~K}$ [39].

$\left[\mathrm{Os}_{3}(\mathrm{CO})_{11}\right]^{2-}$ clusters on the basic support MgO broke up into mononuclear species, $\mathrm{Os}^{2+}(\mathrm{CO})_{2}$, under by reaction with support $\mathrm{OH}$ groups with the sample in helium [58], but the fragmentation temperature of $548 \mathrm{~K}$ is much higher than those mentioned above for fragmentation of metal clusters on acidic supports in $\mathrm{CO}$ or ethylene, and the conversion of the osmium clusters was slow, taking 2 h.

Our observations fit into the pattern of the work mentioned above. The rhodium dimers were fragmented in $\mathrm{CO}$, ethylene, or helium atmospheres, and the temperature $(393 \mathrm{~K})$ was higher than those applied to fragment metal clusters on acidic supports in $\mathrm{CO}$ or ethylene, but lower than that for the breakup of triosmium carbonyl clusters on $\mathrm{MgO}$ in helium. Our fragmentation was slow, requiring $2 \mathrm{~h}$ for an incomplete (5-94\% conversion, Table 3) under all of our conditions. The tendency of the fragmentation to take place in the various gases increased in the order helium < ethylene $<$ CO. Different from the breakup of the abovementioned supported metal carbonyl clusters, the fragmentation of $\mathrm{MgO}$-supported $\mathrm{Rh}_{2}(\mathrm{OAc})_{3}$ was a reductive process, as the formal oxidation state of the rhodium in the dimer decreased from +2 to +1 . We speculate that during the fragmentation, acetate ligands might have been oxidized to form $\mathrm{CO}$ or $\mathrm{CO}_{2}$, but we could not detect either of these products with the mass spectrometer, as the process was slow and these products would have been present in only low concentrations.

4.4. Intermediates in the Fragmentation of Supported Rhodium Dimers

To the best of our knowledge, no intermediate species formed during the fragmentation of supported metal clusters have been reported. Such observations are often challenging because of the rapidity of the fragmentation, the 
lack of stability of the fragments, and the lack of techniques for detecting the fragments as minority species.

In this work, because the fragmentation of $\mathrm{MgO}$ supported $\mathrm{Rh}_{2}(\mathrm{OAc})_{3}$ is slow and intermediates are stable under our treatment conditions, we were able to detect a species identified as a dirhodium without acetate ligands after a pulse of $\mathrm{CO}$, and this dirhodium species was characterized by two bridging carbonyl bands, at 1892 and $1854 \mathrm{~cm}^{-1}$ (Figures 4 and 5 ). Because of the evident lack of acetate ligands on this di-rhodium species to inhibit ethylene hydrogenation catalysis, this species was three orders of magnitude more active than the supported $\mathrm{Rh}_{2}(\mathrm{OAc})_{3}$ (Table 4). Furthermore, because the activity of the dirhodium species without acetate ligands was two orders of magnitude greater than that of supported mononuclear rhodium species, we suggest an effect of the neighboring rhodium centers acting in tandem, but this suggestion remains to be evaluated.

\subsection{Structure Changes of Supported Catalyst under Reac-} tion Conditions

The break-up of small rhodium clusters supported on an acidic zeolite (HY) during ethylene hydrogenation catalysis was characterized by EXAFS spectroscopy.[59] The results showed that rhodium clusters were completely fragmented in less than 10 min under reaction conditions similar with ours. Our IR spectra (Figure 8) demonstrate a similar process on the basic MgO support as well, but it is much slower and incomplete (with about $10 \%$ of the rhodium dimer broken into mononuclear rhodium species after $27 \mathrm{~h}$ of reaction). The effect of the $\mathrm{MgO}$ as a ligand may be an advantage in stabilizing supported metal cluster catalysts, but this suggestion also deserves further scrutiny.

\section{Conclusions}

IR and EXAFS spectroscopies and STEM were used to characterize the supported rhodium dimer formed by chemisorption of $\mathrm{Rh}_{2}(\mathrm{OAc})_{4}$ on $\mathrm{MgO}$ powder. The reaction takes place with loss of approximately one acetate ligand and formation of a bond between rhodium and a $\mathrm{MgO}$ surface oxygen atom. STEM images demonstrated the pairs of $\mathrm{Rh}$ atoms on the support. IR spectra characterizing $\mathrm{CO}$ adsorption on the supported rhodium species demonstrate that they have a high degree of uniformity. IR spectra demonstrate changes in the structure of the supported rhodium species when treated at $353 \mathrm{~K}$ in $\mathrm{CO}$, ethylene, or helium - the supported rhodium dimers were broken up into mononuclear species via an intermediate dirhodium species without acetate ligands, and the fragmentation in the treatment gases increased in the order helium < ethylene < CO. In contrast, the dimeric structure was retained with the sample in $\mathrm{H}_{2}$ at $353 \mathrm{~K}$, but the rhodium was reduced, and, at higher temperatures, it underwent aggregation to form rhodium clusters. The supported rhodium dimers also fragmented under condi- tions of ethylene hydrogenation catalysis at $298 \mathrm{~K}$. Catalyst performance and characterization data indicate that the intermediate dirhodium species without acetate ligands are much more active for ethylene hydrogenation than either supported $\mathrm{Rh}_{2}(\mathrm{OAc})_{3}$ species or mononuclear rhodium species. The cluster fragmentation on the basic support is much less facile than on acidic supports than on $\mathrm{MgO}$, suggesting an advantage of basic supports in terms of catalyst stability.

\section{Acknowledgements}

This work was supported by the U.S. Department of Energy (DOE), Office of Science, Basic Energy Sciences (BES), Grant DE-FGo2-04ER15513. A portion of this work was done as part of the Chemical Imaging Initiative at Pacific Northwest National Laboratory (PNNL) (under Contract DE-ACo576RLo1830), operated for DOE by Battelle. It was conducted under the Laboratory Directed Research and Development Program at PNNL. A portion of the research was performed using EMSL, a national scientific user facility sponsored by the DOE's Office of Biological and Environmental Research and located at PNNL. We acknowledge beam time at beamline 4-1 at the Stanford Synchrotron Radiation Lightsource supported by the DOE Division of Materials Sciences. We thank the beamline staff for valuable support.

\section{Appendix A. Supplementary material}

Experimental details are reported, including IR spectra, STEM images and EXAFS data analysis. Supplementary data associated with this article can be found, in the online version.

\section{References}

[1] P. Serna, B.C. Gates, Acc. Chem. Res. 47 (2014) 2612.

[2] B.T. Qiao, A.Q. Wang, X.F. Yang, L.F. Allard, Z. Jiang, Y.T. Cui, J.Y. Liu, J. Li, T. Zhang, Nat. Chem. 3 (2011) 634.

[3] X.G. Guo, G.Z. Fang, G. Li, H. Ma, H.J. Fan, L. Yu, C. Ma, X. Wu, D.H. Deng, M.M. Wei, D.L. Tan, R. Si, S. Zhang, J.Q. Li, L.T. Sun, Z.C. Tang, X.L. Pan, X.H. Bao, Science, 344 (2014) 616.

[4] J.D. Kistler, N. Chotigkrai, P.H. Xu, B. Enderle, P. Praserthdam, C.Y. Chen, N.D. Browning, B.C. Gates, Angew. Chem. Int. Ed. 53 (2014) 8904.

[5] M. Yang, S. Li, Y. Wang, J.A. Herron, Y. Xu, L.F. Allard, S. Lee, J. Huang, M. Mavrikakis, M. FlytzaniStephanopoulos, Science, 346 (2014) 1498.

[6] J. Lu, P. Serna, C. Aydin, N.D. Browning, B.C. Gates, J. Am. Chem. Soc. 133 (2011) 16186.

[7] D. Yardimci, P. Serna, B.C. Gates, ChemCatChem 4 (2012) 1547.

[8] D. Yardimci, P. Serna, B.C. Gates, ACS Catal. 2 (2012) 2100.

[9] P.W. Kletnieks, A.J. Liang, R. Craciun, J.O. Ehresmann, D.M. Marcus, V.A. Bhirud, M.M. Klaric, M.J. Haymann, D.R. Guenther, O.P. Bagatchenko, D.A. Dixon, B.C. Gates, J.F. Haw, Chem.-Eur. J. 13 (2007) 7294. 
[10] A.J. Liang, V.A. Bhirud, J.O. Ehresmann, P.W. Kletnieks, J.F. Haw, B.C. Gates, J. Phys. Chem. B, 109 (2005) 24236.

[11] A.J. Liang, R. Craciun, M.Y. Chen, T.G. Kelly, P.W. Kletnieks, J.F. Haw, D.A. Dixon, B.C. Gates, J. Am. Chem. Soc. 131 (2009) 8460.

[12] J.C. Matsubu, V.N. Yang, P. Christopher, J. Am. Chem. Soc. 137 (2015) 3076.

[13] J.L. Vidal, W.E. Walker, Inorg. Chem. 19 (1980) 896.

[14] A.M. Argo, J.F. Odzak, J.F. Goellner, F.S. Lai, F.S. Xiao, B.C. Gates, J. Phys. Chem. B 110 (2006) 1775.

[15] A.M. Argo, B.C. Gates, J. Phys. Chem. B, 107 (2003) 5519.

[16] W.F. Graydon, M.D. Langan, J. Catal. 69 (1981) 180.

[17] D.A.J.M. Ligthart, R.A. van Santen, E.J.M. Hensen, Angew. Chem., Int. Ed. 50 (2011) 5306.

[18] F. Hoxha, N. van Vegten, A. Urakawa, F. Krurneich, T. Mallat, A. Baiker, J. Catal. 261 (2009) 224.

[19] S.M. McClure, M.J. Lundwall, D.W. Goodman, Proc. Natl. Acad. Sci. U.S.A. 108 (2011) 931.

[20] K. Ito, H.J. Bernstein, Can. J. Chem. 34 (1956) 170.

[21] C. Xu, B.E. Koel, J. Chem. Phys. 102 (1995) 8158.

[22] Q.X. Ma, Y.C. Liu, C. Liu, H. He, Phys. Chem. Chem. Phys. 14 (2012) 8403.

[23] C. Chizallet, G. Costentin, M. Che, F. Delbecq, P. Sautet, J. Am. Chem. Soc. 129 (2007) 6442.

[24] E. Knözinger, K.H. Jacob, S. Singh, P. Hofmann, Surf. Sci. 290 (1993) 388.

[25] R.J.H. Clark, Chem. Soc. Rev. 19 (1990) 107.

[26] F.A. Cotton, B.G. Deboer, M.D. Laprade, J.R. Pipal, D.A. Ucko, Acta Crystallogr. B 27 (1971) 1664.

[27] S. Mehraeen, A. Kulkarni, M.F. Chi, B.W. Reed, N.L. Okamoto, N.D. Browning, B.C. Gates, Chem.-Eur. J. 17 (2011) 1000.

[28] A. Kulkarni, M.F. Chi, V. Ortalan, N.D. Browning, B.C. Gates, Angew. Chem., Int. Ed. 49 (2010) 10089.

[29] R.B. Duarte, O.V. Safonova, F. Krumeich, J.A. van Bokhoven, Phys. Chem. Chem. Phys. 16 (2014) 26553.

[3o] Z.W. Chen, S. Fujita, K. Fukui, J. Phys. Chem. C 115 (2011) 14270.

[31] E.B. Boyar, S.D. Robinson, Coord. Chem. Rev. 50 (1983) 109.

[32] R. Paulisse, H. Reimling, E. Hayez, A.J. Hubert, P. Teyssie, Tetrahedron Lett. (1973) 2233.

[33] A.J. Hubert, A. Feron, R. Warin, P. Teyssie, Tetrahedron Lett. (1976) 1317.

[34] A.J. Anciaux, A. Demonceau, A.J. Hubert, A.F. Noels, N. Petiniot, P. Teyssie, J. Chem. Soc., Chem. Comm. (1980) 765.

[35] M.P. Doyle, Chem. Rev. 86 (1986) 919.

[36] E.A. Wovchko, J.T. Yates, J. Am. Chem. Soc. 120 (1998) 10523.

[37] C.A. Rice, S.D. Worley, C.W. Curtis, J.A. Guin, A.R. Tarrer, J. Chem. Phys. 74 (1981) 6487.

[38] K. Asakura, K. Kitamurabando, Y. Iwasawa, H. Arakawa, K. Isobe, J. Am. Chem. Soc. 112 (1990) 9096.

[39] P. Serna, D. Yardimci, J.D. Kistler, B.C. Gates, Phys. Chem. Chem. Phys. 16 (2014) 1262.

[4o] D. Yardimci, P. Serna, B.C. Gates, Chem.-Eur. J. 19 (2013) 1235.

[41] I. Ogino, B.C. Gates, J. Phys. Chem. C 114 (2010) 8405.

[42] P. Serna, B.C. Gates, J. Catal. 308 (2013) 201.
[43] E.J. Rode, M.E. Davis, B.E. Hanson, J. Catal. 96 (1985) 574.

[44] W.A. Weber, B.L. Phillips, B.C. Gates, Chem. Eur. J. 5 (1999) 2899.

[45] W.A. Weber, B.C. Gates, J. Phys. Chem. B 101 (1997) 10423.

[46] M.E. Davis, E. Rode, D. Taylor, B.E. Hanson, J. Catal. 86 (1984) 67.

[47] N.D. Triantafillou, B.C. Gates, J. Phys. Chem., 98 (1994) 8431.

[48] S. Kawi, J.R. Chang, B.C. Gates, J. Phys. Chem. 97 (1993) 5375.

[49] H.H. Lamb, B.C. Gates, J. Am. Chem. Soc. 108 (1986) 81.

[5o] R. Psaro, C. Dossi, R. Ugo, J. Mol. Catal. 21 (1983) 331.

[51] F.S. Lai, B.C. Gates, Nano Lett. 1 (2001) 583.

[52] K.K. Bando, K. Asakura, H. Arakawa, K. Isobe, Y. Iwasawa, J. Phys. Chem. 100 (1996) 13636.

[53] A. Berko, G. Menesi, F. Solymosi, J. Phys. Chem. 100 (1996) 17732.

[54] A. Berko, F. Solymosi, J. Catal. 183 (1999) 91.

[55] A. Suzuki, Y. Inada, A. Yamaguchi, T. Chihara, M. Yuasa, M. Nomura, Y. Iwasawa, Angew. Chem., Int. Ed. 42 (2003) 4795 .

[56] A.J. Liang, B.C. Gates, J. Phys. Chem. C 112 (2008) 18039.

[57] A. Uzun, B.C. Gates, Angew. Chem., Int. Ed. 47 (2008) 9245 .

[58] C. Aydin, A. Kulkarni, M.F. Chi, N.D. Browning, B.C. Gates, J. Phys. Chem. Lett. 3 (2012) 1865.

[59] P. Serna, B.C. Gates, J. Am. Chem. Soc. 133 (2011) 4714. 
Graphical Abstract

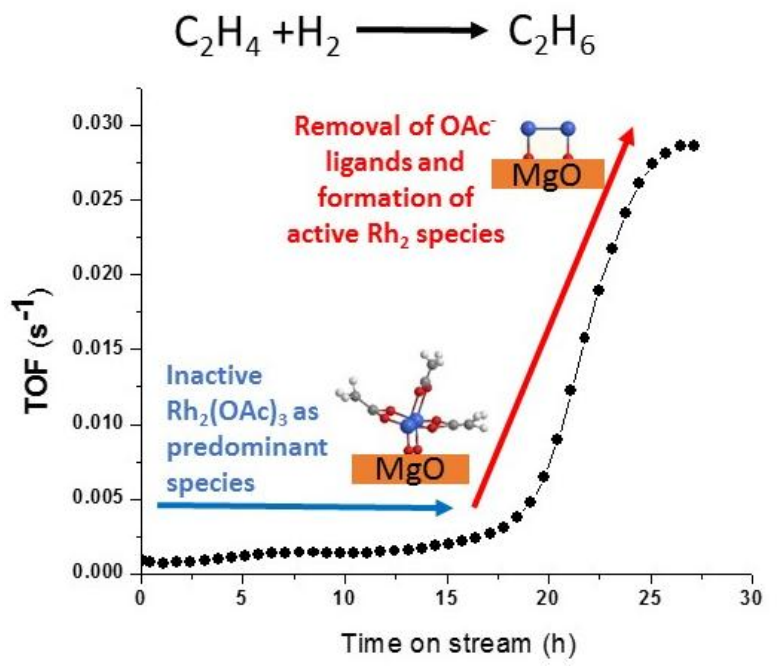

